\title{
Why is the Arkavathy River drying? A multiple-hypothesis approach in a data-scarce region
}

\author{
V. Srinivasan ${ }^{1}$, S. Thompson ${ }^{2}$, K. Madhyastha ${ }^{1}$, G. Penny ${ }^{2}$, K. Jeremiah ${ }^{1}$, and S. Lele ${ }^{1}$ \\ ${ }^{1}$ Ashoka Trust for Research in Ecology and the Environment, Royal Enclave Sriramapura, Jakkur Post, \\ Bangalore, Karnataka, India \\ ${ }^{2}$ Department of Civil and Environmental Engineering, University of California, Berkeley, Berkeley, California, USA \\ Correspondence to: V. Srinivasan (veena.srinivasan@atree.org)
}

Received: 16 November 2014 - Published in Hydrol. Earth Syst. Sci. Discuss.: 6 January 2015

Revised: 20 March 2015 - Accepted: 20 March 2015 - Published: 22 April 2015

\begin{abstract}
Water planning decisions are only as good as our ability to explain historical trends and make reasonable predictions of future water availability. But predicting water availability can be a challenge in rapidly growing regions, where human modifications of land and waterscapes are changing the hydrologic system. Yet, many regions of the world lack the long-term hydrologic monitoring records needed to understand past changes and predict future trends.

We investigated this "predictions under change" problem in the data-scarce Thippagondanahalli (TG Halli) catchment of the Arkavathy sub-basin in southern India. Inflows into TG Halli reservoir have declined sharply since the 1970s. The causes of the drying are poorly understood, resulting in misdirected or counter-productive management responses.

Five plausible hypotheses that could explain the decline were tested using data from field surveys and secondary sources: (1) changes in rainfall amount, seasonality and intensity; (2) increases in temperature; (3) groundwater extraction; (4) expansion of eucalyptus plantations; and (5) fragmentation of the river channel. Our results suggest that groundwater pumping, expansion of eucalyptus plantations and, to a lesser extent, channel fragmentation are much more likely to have caused the decline in surface flows in the TG Halli catchment than changing climate.

The multiple-hypothesis approach presents a systematic way to quantify the relative contributions of proximate anthropogenic and climate drivers to hydrological change. The approach not only makes a meaningful contribution to the policy debate but also helps prioritize and design future research. The approach is a first step to conducting use-inspired socio-hydrologic research in a watershed.
\end{abstract}

\section{Introduction}

Freshwater has been identified as one of the gravest challenges of the twenty-first century (Wagener et al., 2010; Vörösmarty et al., 2010; Srinivasan et al., 2012a). Human demands for water have increased while annual freshwater available globally has remained more or less constant through history. To make sound policy choices, water managers need to know how water availability is changing. They must reconcile the ability to meet the needs of their populations and economies with the potential impacts on the wellbeing of downstream users, ecosystems and/or future generations. But predicting water availability is particularly challenging in rapidly growing regions, which are undergoing population growth, agricultural intensification and industrialization. Human modifications of land and waterscapes are changing the dynamics of the water cycle at unprecedented rates. Many of these regions also lack the long-term hydrologic monitoring records needed to make such analyses possible. As a result, water managers lack the scientific basis to articulate trade-offs. This often leads to policies that address only part of the problem at best or, at worst, have negative or paradoxical outcomes (Sivapalan et al., 2014).

\subsection{Challenges in rapidly growing, data-scarce regions}

Making hydrological predictions is a non-trivial problem in any context, but it is confounded by three issues encountered in rapidly changing, data-scarce regions: (i) non-stationarity arising from anthropogenic drivers, (ii) the sparse availability of historical data, and (iii) lack of original, place-based scientific research leading to oversimplified assumptions. The 
prediction challenges arise both from the nature of the system (point i) and researcher constraints (points ii and iii), but the net result is that water managers are forced to rely on conceptual models that poorly represent the underlying system.

Multiple drivers of change: traditional water resources management is based on the assumption of stationarity - the idea that natural systems fluctuate within an unchanging envelope of variability (Milly et al., 2008). However, the impact of humans on the water cycle, either directly through modification of landscapes and waterscapes, or indirectly via climate change, has been identified as a defining challenge for hydrology (Thompson et al., 2013). The potential impacts of climate change on the hydrologic cycle have received enormous attention from researchers and decision makers in recent years (Stocker and Raible, 2005; Huntington, 2006). The role of other direct human interventions like groundwater extraction, small dams and urbanization is also coming under increased scrutiny (Arrigoni et al., 2010; Wang and Hejazi, 2011; Cai and Zeng, 2013; Zeng and Cai, 2014; Hu et al., 2015).

Data sparseness: the task of determining cause and effect relationships with respect to hydrologic behaviour is complicated in regions with sparse or recent hydrologic records (Maeda and Torres, 2012; Systematics, 2010). Despite long-standing global calls to improve data sharing and transparency (Arzberger et al., 2004; Sivapalan et al., 2003; Bonell et al., 2006; Reichman et al., 2011; Dunne and Leopold, 1978), data scarcity remains an impediment to research in many parts of the world. Data scarcity has motivated concerted research efforts such as the predictions in ungauged basins (PUB) effort of IAHS (Wagener et al., 2004; Sivapalan, 2003; Sivapalan et al., 2003). However, these efforts are generally not suitable for predictions in nonstationary, human-impacted basins (Srinivasan et al., 2012b; Sivapalan et al., 2012). In such cases, lack of data confounds both conceptual understanding and building of quantitative models that explain how the water system works.

Over-simplifying assumptions: investments in the water sector must be made even in the absence of long-term records. In the absence of reliable data, modellers are then often forced to make many simplifying assumptions. The choices seem too often to be dictated by what can be modelled rather than what matters, leading to so-called "modeller myopia" (Buytaert, 2015). For instance, Gosain et al. (2006) predict water availability in space and time in several Indian river basins under climate change, but they do not incorporate man-made structures like dams or diversions into their basic model or trend analyses. Mujumdar and Ghosh (2008) modelled flows in the Mahanadi of eastern India; their model assumed that recent declines in streamflow reflect a "climate signal", without considering the possible influence of more proximate factors like groundwater pumping. Similarly, numerous water resources modelling projects in India decouple the effects of groundwater depletion from surface water responses, even where groundwater overexploitation is known to be a problem (Kelkar et al., 2008; Gosain et al., 2011; Garg et al., 2013).

\subsection{Use-inspired science in data-scarce regions}

The mismatch between the needs of water managers and what off-the-shelf models can generate is not a sufficient reason for inaction or ad hoc decision making in regions with rapidly increasing water demand. There is an urgent need to formulate new approaches to frame and conduct hydrologic investigations in human-dominated, data-scarce situations. The conventional response would be to initiate primary data collection and to build new site-specific models from scratch. However, hydrologic data collection is expensive and takes many years. In contrast, information is often needed quickly and projects are limited by time and resource constraints.

How should hydrologists proceed in these circumstances? First, as Thompson et al. (2013) suggest, hydrologists should adopt a "use-inspired science" approach by pursuing scientific understanding while also addressing policy and management goals. This requires identifying the most pressing societal problems and working backwards from them. Second, as Buytaert et al. (2014) suggest, knowledge may be dispersed amongst multiple parties. While researchers and managers may hold some expert knowledge, citizens who have lived through change in the basin may also have useful insights. Third, it should be possible to use this knowledge to identify working hypotheses (Chamberlin, 1965) that might explain the hydrological phenomenon of interest, and then use the sparse data to accept or reject at least some of them. This approach would then guide the choice of future data collection and sophisticated modelling efforts, targeting the most critical knowledge gaps. We use the above approach to narrow down possible causal mechanisms of hydrologic change in the Arkavathy watershed in southern India. Five possible hypotheses that link anthropogenic and climatic changes to the water scarcity in the watershed are outlined and investigated.

\section{The problem: drying of TG Halli reservoir}

\subsection{Description of study area}

The Arkavathy River is located in the state of Karnataka in southern India (Fig. 1). The river's catchment overlaps with the western portion of the rapidly growing metropolis of Bengaluru (Bangalore). The region is seasonally monsoonal, receiving approximately $830 \mathrm{~mm}$ of precipitation annually. The main stem of the Arkavathy River has its headwaters in the Nandi Hills north of Bengaluru and is joined by its first major tributary, the Kumudvathy River at Thippagondanahalli (TG Halli) village, where a reservoir was constructed in 1935 to supply water to Bengaluru. This reservoir has a catchment area of approximately $1447 \mathrm{~km}^{2}$. 


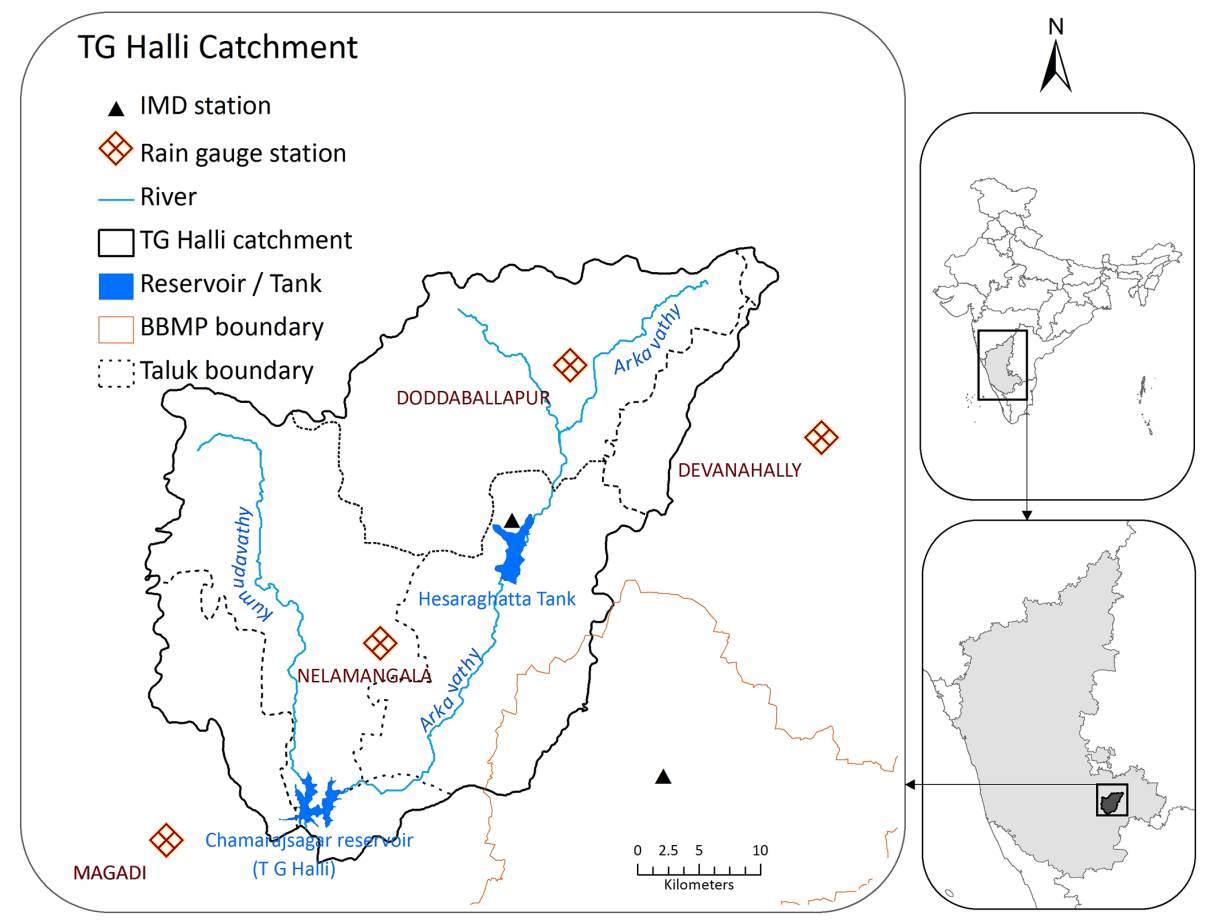

Figure 1. The TG Halli catchment with major features. BBMP is the Greater Bangalore Municipal Corporation Boundary (data source: Survey of India toposheets at 1:50000 scale; ASTER DEM imagery, maps prepared at the ATREE EcoInformatics Lab).

The TG Halli reservoir catchment also contains an older water supply reservoir at Hesaraghatta, as well as an estimated 617 small surface storage structures called "tanks". Tanks are traditional in-stream water harvesting systems that were commonly built in southern India and Sri Lanka over the last 6 centuries to store monsoon runoff for post-monsoon irrigation (Vaidyanathan, 2001; Shah, 2003). The cumulative storage of all these tanks (297 of which are more than 50 ha in size) and Hesaraghatta reservoir is estimated to be 143 million cubic metres, i.e. about 1.5 times the storage capacity of TG Halli reservoir (ISRO and IN-RIMT, 2000).

Most of the TG Halli catchment is underlain by gneissic and granitic aquifers. Highly weathered soils extend to about $20 \mathrm{~m}$ below grade level (b.g.1.), and form a shallow aquifer in which seasonal perched water tables can develop. Between about 20 and $60 \mathrm{~m}$ b.g.l. lies a fractured rock zone with considerable jointing and cracking, acting as a deeper aquifer. Groundwater yields decline beyond $60 \mathrm{mb}$ b.g.l., although fractures continue to be encountered down to $300 \mathrm{~m}$.

\subsection{The problem}

From 1937 up to the 1980s, the TG Halli reservoir was a major source of water for Bengaluru. However, inflow to the reservoir has steadily declined since the early 1980s (Fig. 2a), and today it supplies only $0-25 \%$ of its design capacity. Average inflows into the TG Halli reservoir have decreased from 385 millions of litres (ML) per day (140000 $\mathrm{ML} \mathrm{year}^{-1}$ ) pre-

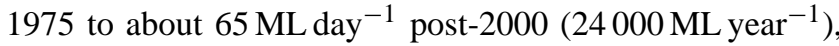
a decline of $320 \mathrm{MLday}^{-1}$. The cascading irrigation tanks dotting the catchment are also mostly dry, indicating that the loss of surface runoff has occurred throughout the catchment (Lele et al., 2013).

The drying of flows into the TG Halli reservoir and tanks in the catchment has clear implications for the 800000 people that live in the catchment, both in terms of current water availability and because the declining flows may be an indicator of the overall unsustainability of water use in the basin jeopardizing future populations and economic growth.

\subsection{The debate about causes and solutions}

Given the urgency of the problem, several uncoordinated and often contradictory actions have been undertaken. One reason for this is that the causes of the inflow reductions to the TG Halli reservoir remain unclear. In order to formulate hypotheses that could be investigated systematically, we consulted a range of sources to understand the positions and perceptions of different groups: one-on-one meetings with government officials, written policy documents and reports, a comprehensive literature review (Lele et al., 2013) and an expert consultation meeting held at ATREE (Bangalore) in November 2012. Additionally, at the launch of the research project in early 2013 , a meeting was convened by the chief secretary of the state which included the research team and the heads of all government agencies engaged in water is- 


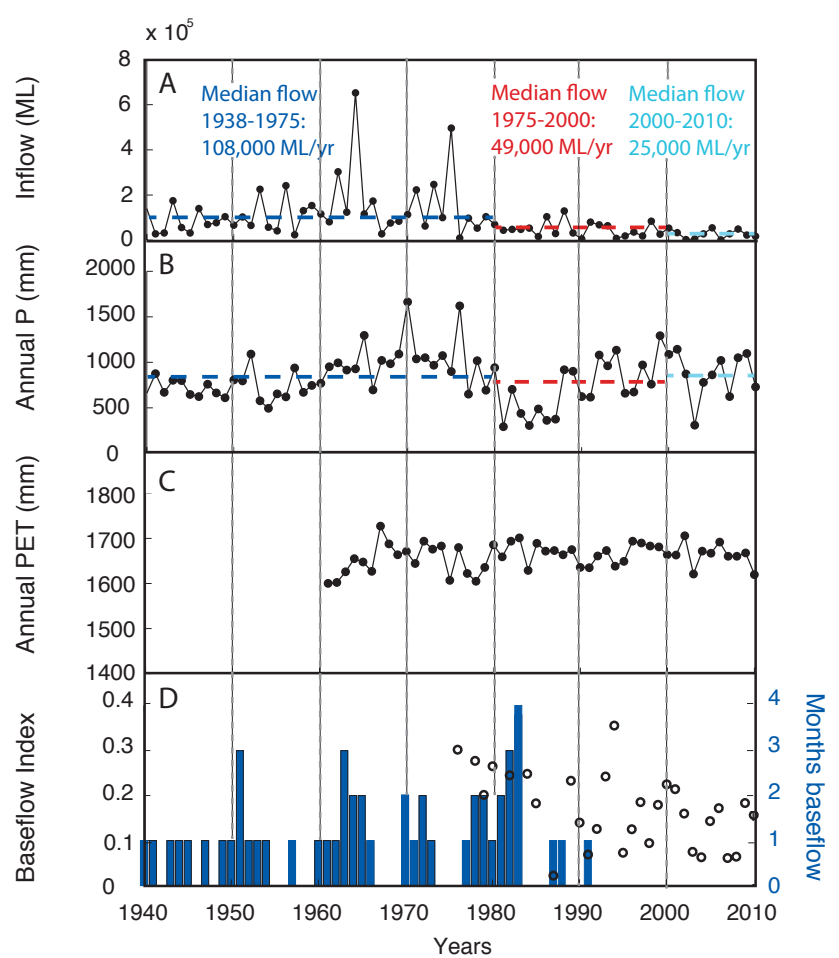

Figure 2. Changes in hydrology and hydrometeorology of the Arkavathy Basin, 1970-2010. (a) Annual inflows into the TG Halli reservoir. The 1938-1975, 1975-2000 and 2000-2010 median and mean annual inflows illustrate the decline in inflow that has occurred in recent decades. (b) Areally averaged annual rainfall over the seventh taluk (local government areas) comprising the TG Halli catchment. Potential evapotranspiration as estimated from the Hargreaves equation for the TG Halli catchment. (d) Two estimates of baseflow contribution to the TG Halli inflows: the number of months/year when $100 \%$ of flow was derived from baseflow (bars) and the baseflow index computed from daily inflow data (dots).

sues. The research team also made several reconnaissance visits, attended over a dozen stakeholder meetings hosted by other groups and held more than 60 "water literacy meetings" in the TG Halli catchment villages in 2014 and 2015, which were collectively attended by over 500 farmers. Finally, the research team conducted over two dozen focus group discussions in 2013 and 2014, targeting specific stakeholder groups.

This initial review identified several policy positions that reflect different perceptions on the drying of the river:

- The Bangalore Water Supply and Sewerage Board (BWSSB), which owns and operates the TG Halli reservoir, commissioned a study (ISRO and IN-RIMT, 2000). This study identified several possible causes for the decline of inflows into the TG Halli - declines in rainfall, groundwater pumping and obstructions in streams. However, the study did not quantify the relative magnitudes of these factors and did not recommend actions to directly address them. BWSSB has taken no specific actions of its own to address the problem.

- The Cauvery Neeravari Nigam Ltd. (CNNL) was made responsible by the state government for "rejuvenating" the Arkavathy River. CNNL commissioned its own study (CNNL, 2010), which concluded that the primary reason for reduced inflow into TG Halli is obstructions in the channels. Accordingly, the agency response has been to bulldoze the obstructions and desilt the channels.

- Meanwhile, local rural development programmes have focused on constructing check dams to recharge the shallow aquifer and ostensibly restore baseflow in the stream.

- A number of urban based citizen's groups have emerged with the objective of rejuvenating the river or saving Bangalore's water bodies (see http://www. artofliving.org/kumudvathi-river-rejuvenation-project and https://www.facebook.com/arkavathi.rejuvenation). These groups are focused on removal of eucalyptus trees, desilting lake beds and diverting treated wastewater into lakes to recharge the shallow aquifer.

- The state Water Resources Development Organization (WRDO) has argued that climate change, via declining rainfall and rising temperatures, is responsible for the drying of the river. This perception was also held by most farmers we interacted with during the water literacy meetings, many of whom favour inter-basin imports from west-flowing rivers.

\subsection{The multiple-hypothesis approach}

By examining the different explanations of the causes of streamflow decline and plausible runoff generation mechanisms, we identified and investigated all plausible hypotheses that could explain the observed changes in the Arkavathy Basin:

- Hypothesis 1: changes in rainfall: changes in rainfall as the primary driver of streamflow could induce changes in surface runoff generation. The climate change literature for this part of Karnataka mentions a possible shift in the monsoon, such that the south-west monsoon June-July-August-September (JJAS) season rainfall would probably decline, and post-monsoon October-November-December (OND) rainfall could increase. A change in the seasonality of precipitation could result in a change in rainfall partitioning to runoff, because a greater fraction is partitioned to evaporation and transpiration. Additionally, if both seasonal and annual rainfall patterns are unchanged, a reduction in the mean storm intensity or depth could result in a failure to trigger infiltration-excess or saturation-excess runoff. 

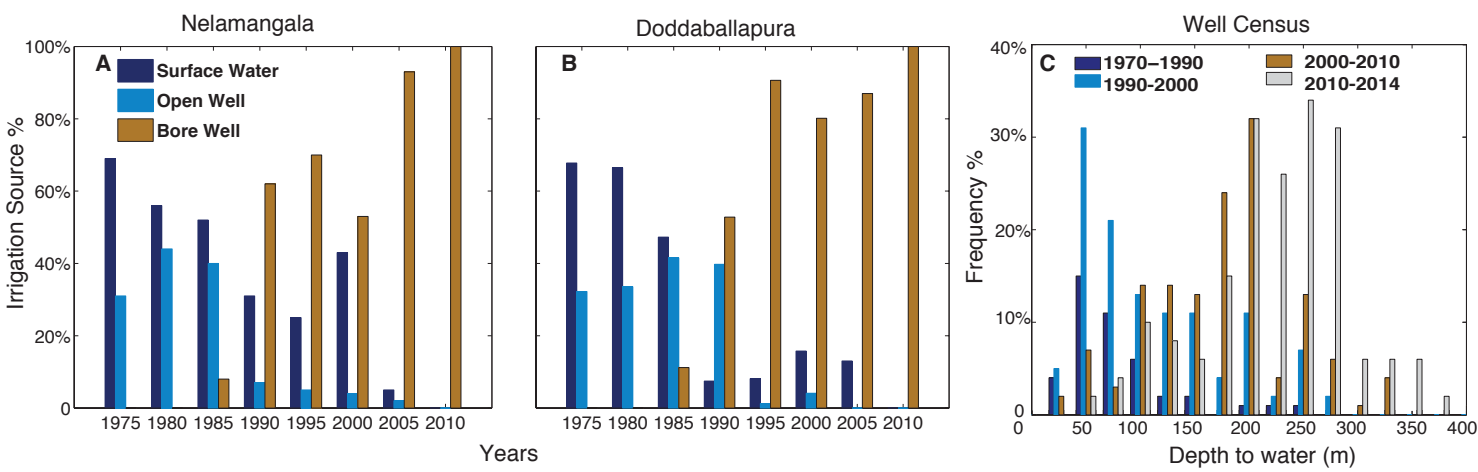

Figure 3. Water use in the TG Halli catchment. (a, b) Sources of irrigation water used over time in two taluks (local government areas), indicating the reduction in surface and shallow well use and their replacement by deep borehole over time. Data Source: Department of Economics and Statistics, Karnataka. (c) Depths at which water was encountered at time of drilling. Data from well census conducted by ATREE field hydrology team in summer of 2014 covering 482 boreholes in a $26 \mathrm{sq} \mathrm{km}$ area in TG Halli catchment.

The previous study commissioned by BWSSB found that rainfall in excess of $20 \mathrm{~mm} \mathrm{day}^{-} 1$ is needed to generate significant inflows into TG Halli reservoir (ISRO and IN-RIMT, 2000).

- Hypothesis 2: increasing potential evapotranspiration due to climate change: increases in potential evapotranspiration could result in an increase in actual evapotranspiration, reducing recharge and therefore baseflow. Of the major drivers of potential evapotranspiration (temperature, humidity, solar radiation and wind speed), it is known that temperature has been increasing in southern India over the past century, with most stations reporting temperature increases on the order of $1^{\circ} \mathrm{C} / 100$ years (Arora et al., 2005; Hingane et al., 1985). On the other hand, solar radiation trends in the region have been negative, in association with the formation of atmospheric brown clouds (Ramanathan et al., 2005), and wind speed trends in India also appear to also be declining (McVicar et al., 2012). Empirical evidence from evaporation gauges throughout India also suggests that pan evaporation has declined over the twentieth century (Chattopadhyay and Hulme, 1997). Nonetheless, temperature-driven increases in evaporative demand could have altered rainfall-runoff partitioning in the catchment and contributed to the reduced streamflow.

- Hypothesis 3: declining baseflow due to groundwater overexploitation: previous studies in well-monitored basins have shown that groundwater depletion can reduce baseflow contributions to streamflow, reducing overall flows (Cai and Zeng, 2013; Zeng and Cai, 2014). Our hypothesis is that reduction in groundwater storage induced by pumping lowers the seasonal water table, resulting in the water table intersecting the river channel less frequently and for shorter periods of time, ultimately reducing the baseflow contribution to the Arka- vathy. The decline in the Arkavathy River flow has occurred concurrently with an expansion of groundwater extraction in the basin and across Karnataka. Although groundwater monitoring in the region is minimal, irrigation data clearly show a shift from surface to groundwater and open wells to deep boreholes (Fig. 3a, b) (DES, 1970-2012).

\section{- Hypothesis 4: increasing actual evapotranspiration due} to expansion of plantations: numerous studies indicate that where a catchment area is converted from rain-fed agriculture to deep-rooted perennial vegetation, it can result in decreases in flow (Brown et al., 2005). Eucalyptus cultivation was actively promoted among farmers by the state government under its farm forestry programme in the 1980s (Shiva et al., 1981). Field surveys within the TG Halli catchment indicate a significant increase in eucalyptus plantation area in the past 40 years. Several studies have documented that eucalyptus plantations create unsaturated conditions over a deep root zone and can thus reduce subsurface contributions to streamflow (Calder et al., 1993; Farley et al., 2005).

- Hypothesis 5: million puddle theory: the final hypothesis is that the construction of (largely illegal) structures in the channel - along with construction of check dams and unculverted roads - has resulted in the channels in the upper catchment becoming disconnected. In other words, a once-connected, flowing river has been replaced by a "million puddles". A portion of the water in these puddles evaporates or is transpired by riparian vegetation and becomes unavailable. 
Table 1. Details of various data sets used.

\begin{tabular}{|c|c|c|}
\hline Parameter & Type of data & Source of data \\
\hline Precipitation & $\begin{array}{l}\text { Daily rainfall from four rain gauges } \\
(1934-2010)\end{array}$ & Indian Meteorological Department \\
\hline Temperature & $\begin{array}{l}\text { Monthly max., min. and mean } \\
\text { temperature from two weather stations } \\
(1901-2010)\end{array}$ & Indian Meteorological Department \\
\hline Surface flow & $\begin{array}{l}\text { Daily inflows (1975-2010) and } \\
\text { Monthly inflows (1937-2010) into TG } \\
\text { Halli reservoir }\end{array}$ & $\begin{array}{l}\text { Bangalore Water Supply and Sewerage } \\
\text { Board }\end{array}$ \\
\hline $\begin{array}{l}\text { Area under eucalyptus plantations in } \\
1973-1979\end{array}$ & Topographical sheet & Survey of India \\
\hline Area under eucalyptus in 2001 & Land use map & $\begin{array}{l}\text { Karnataka State Remote Sensing } \\
\text { Applications Centre }\end{array}$ \\
\hline Groundwater levels & $\begin{array}{l}\text { Well census of } 472 \text { wells in two } \\
\text { milli-watersheds covering } 26 \mathrm{~km}^{2}\end{array}$ & ATREE hydrology team field survey \\
\hline \multirow[t]{2}{*}{ Groundwater extraction } & Irrigated area (1970-2012) & KA State Annual Season Crop Report \\
\hline & Irrigated area $(1981,1991,2001)$ & $\begin{array}{l}\text { Census of India, Village Amenities } \\
\text { Dataset }\end{array}$ \\
\hline \multirow[t]{2}{*}{ Channel obstructions } & $\begin{array}{l}\text { Number of check dams and uncul- } \\
\text { verted } \\
\text { roads }\end{array}$ & Primary Survey by Zoomin Tech. \\
\hline & $\begin{array}{l}\text { Number of check dams in two } \\
\text { milli-watersheds covering } 26 \mathrm{~km}^{2}\end{array}$ & ATREE hydrology team field survey \\
\hline
\end{tabular}

\section{Methods}

\subsection{Data sources and quality assurance}

To test these hypotheses, we collected available secondary data within and around the Arkavathy Basin. Data were quality-checked and triangulated against other sources and supplemented with field surveys when needed (Table 1).

Monthly inflow data for the TG Halli reservoir were obtained from Bangalore Water Supply and Sewerage Board (BWSSB) for the period 1937 to 2010. Additionally, daily records of inflows from 1970 onwards were obtained from the local BWSSB offices and digitized. The daily and monthly data were cross-validated and any errors were corrected.

\subsection{Analysis techniques}

The goal of the analysis was two-fold: (i) to determine whether the perceived changes in hydrological drivers have occurred and (ii) whether the magnitude of changes in the drivers could explain the magnitude of the change in flow in the Arkavathy Basin (i.e. consistent with the observed $320 \mathrm{ML} \mathrm{day}^{-1}$ reductions in flow).

\section{Hypothesis 1: declining rainfall}

Data from four long-term rainfall gauges located in Devanahalli, Doddaballapura, Magadi and Nelamangala towns within the TG Halli catchment were available for analysis (see Fig. 1 for gauge locations). These gauges provide daily rainfall data over 75 years (1934-2010). Although 18 additional rainfall gauges, operated by various government agencies, exist within the catchment, these gauges do not provide continuous data over a sufficient time period to allow trend analysis. As a quality control procedure, we performed double mass plots, compared the total number of rainy days between the gauges, and excluded years where the total number of rainy days represented a low outlier (indicating a likelihood of missing data). Outlier years were determined to be those where the number of recorded rain days was less than $f_{25}-1.5\left(f_{75}-f_{25}\right)$, where $f_{75}$ represents the 75 th percentile and $f_{25}$ the 25th percentile of the total number of rain days.

Annual rainfall was computed over the water year (June to May). Seasonal rainfall totals were computed in terms of pre-monsoon (January-February-March-April-May: JFMAM), monsoon (June-July-August-September: JJAS) and post-monsoon (October-November-December: OND) rainfall totals. To identify changes in rainfall depths at daily 
timescales, the number of days per year in which rainfall volumes exceeded 10, 25 and $50 \mathrm{~mm}$ were determined for the 1934-2009 period. Trend detection was undertaken for each of the above data sets in two ways. First, we determined whether a trend was present over the full time series. As the data generally did not conform to the assumptions for least-squares regression, we evaluated the trends using a non-parametric Mann-Kendall test. Second, we evaluated whether a change in the mean values of the meteorological parameters had occurred from the pre-1970 and post-1970 period, taking 1970 as a point after which the Arkavathy River flows obviously declined. Where the data were normally distributed we made these comparisons with $t$ tests; otherwise non-parametric Mann-Whitney-Wilcoxon tests were used.

\section{Hypothesis 2: increasing potential evaporation due to climate change}

In the absence of detailed meteorological data in the Arkavathy Basin, we estimated changes in the mean daily potential evaporation rate as a function of temperature (PET) using the modified 1985 Hargreaves evapotranspiration equation (Hargreaves and Samani, 1985):

$\mathrm{PET}=0.0023 \times R_{a} \times(\mathrm{TC}+17.8) \times \mathrm{TR}^{0.5}$,

where $R_{a}$ is the extraterrestrial solar radiation $\left(\mathrm{mm} \mathrm{day}^{-1}\right)$, and TC is the average daily temperature $\left({ }^{\circ} \mathrm{C}\right)$ calculated as $\left(T_{\mathrm{Max}}+T_{\mathrm{Min}}\right) / 2$. TR is the temperature range $\left(\mathrm{TR}=T_{\mathrm{Max}}-\right.$ $T_{\text {Min }}, T_{\mathrm{Max}}$ is the maximum daily temperature and $T_{\mathrm{Min}}$ is the minimum daily temperature). All results were averaged to the annual timescale. The resulting PET time series was analysed to determine the presence of trends or step changes in the mean PET. Temperature data from 1901 to 2001 were obtained for one station each in Bangalore Urban and Bangalore Rural districts from the Indian Meteorological Department. The data were checked to ensure that there were no missing data and that temperatures were within expected ranges. Extraterrestrial solar radiation was computed based on the weather station latitudes (Maurer, 2014) using the method of Spencer (1971), with an accuracy of $0.01 \%$ (Duffie and Beckman, 2013).

The modified Hargreaves equation relies on the diurnal temperature range to provide a surrogate for solar radiation and is widely used to estimate potential evaporation when only limited ground data (temperature) are available. The resulting PET estimates are typically within $10 \%$ or better of those derived from lysimeter or Penman-Monteith methods, when results are averaged over 5-day or greater time periods (Hargreaves and Allen, 2003). Limitations of the method lie in the fact that the relationship between diurnal temperature range and other drivers of potential evaporation (e.g. net radiation and vapour pressure deficit) may not be stationary over long time periods. In southern India, such non-stationarity is likely to be associated with so-called "solar dimming" due to increased upper atmospheric pollution (Chattopadhyay and Hulme, 1997). We anticipate that errors due to nonstationarity are likely to lead to an over-estimation of potential evaporation via the Hargreaves equation.

\section{Hypothesis 3: declining baseflow due to groundwater overexploitation}

Long-term groundwater level data ( $>10$ years) existed for only two shallow wells within a $5 \mathrm{~km}$ buffer of the TG Halli catchment. These reported stable water levels of 10 $30 \mathrm{~m}$ b.g.l. However, in the course of extensive field visits, no water was seen in any other open well in the region. We concluded that the two monitoring wells are not representative of surrounding conditions. There are also no deep borehole piezometers with long-term water level data in the catchment area. To infer potential changes in groundwater levels, we conducted a comprehensive census of boreholes in a $26 \mathrm{~km}^{2}$ area in the TG Halli catchment in the summer of 2014. Data for a total of 472 boreholes were recorded. For each borehole, the owner was interviewed to obtain details of the year of construction, use, status, depths of yielding fractures and year of failure (if applicable). Together, these data provide an understanding of how groundwater levels have changed in the last 4 decades.

We undertook two different analyses to explore whether changes in groundwater were compatible with the observed changes in surface flow. In one analysis we used a baseflow recession technique to benchmark the changes in mobile subsurface water storage that would be needed to account for the decline in annual flows and then estimated how these changes might manifest as a decline in groundwater levels. If this change in storage greatly exceeds observed well declines in the catchment, then the hypothesis that lower groundwater levels have led to streamflow reductions could be rejected. In a second analysis, we performed a baseflow separation on the daily runoff data from 1970 onwards to determine how the trends in total streamflow were reflected by changes in quick-flow and baseflow.

Recession analysis: we follow Brutsaert and Nieber (1977) in positing a nonlinear relationship between storage $(S$, $[\mathrm{ML}])$ and discharge $\left(Q,\left[\mathrm{ML} \mathrm{day}^{-1}\right]\right)$ of the form

$S=a Q^{b}$.

A mass balance during periods of flow recession (i.e. when rainfall $P$ is negligible) would be given by

$\frac{\mathrm{d} S}{\mathrm{~d} t}=-\mathrm{ET}-Q$,

where recharge to groundwater and inter-basin transfers are assumed negligible and ET represents evapotranspiration. If Eqs. (2) and (3) are coupled and differentiated, then the following expression is obtained relating flow to its rate of 
change:

$a b Q^{b-1} \frac{\mathrm{d} Q}{\mathrm{~d} t}=-\mathrm{ET}-Q$

Under the assumptions that ET is slow in comparison to flow, so that ET $\rightarrow$ 0, Eqs. (3) and (4) simplify to

$$
\frac{\mathrm{d} Q}{\mathrm{~d} t}=-\frac{1}{a b} Q^{2-b} \text {. }
$$

Taking the logarithms of the absolute values of this expression, one obtains

$\log \left(\frac{\mathrm{d} Q}{\mathrm{~d} t}\right)=\log \left(\frac{1}{a b}\right)+(2-b) \log (Q)$.

That is, a plot of the logarithms of the rate of change of the discharge against the logarithms of the actual discharge at any point in time contains sufficient information (in the form of an intercept and slope) to estimate the parameters of the original storage-discharge expression. To do this, the lower envelope of the expression must be fitted in order to minimize the effects of neglecting evaporation and to focus the analysis on the groundwater response (Brutsaert and Nieber, 1977). No significant changes in the recession behaviour over time were identified from this analysis.

This methodology was applied to the monthly flow data from the Arkavathy at TG Halli, focusing on the seasonal recessions from 1937 to 1970 (i.e. prior to the discernible reductions in river flow). There are two major limitations to using monthly data for this analysis. First, the estimation of the rate of change of the flow is coarse. Second, the contribution of rainfall to runoff events is unlikely to be negligible, even during the seasonal recession. However, because the daily flow data were only available for the post-1970 period, the monthly analysis provides the only opportunity to evaluate the storage-discharge relationship when the river was flowing "normally". As outlined in the results, the calibrated model had an exponent $b=1.43$, very close to the theoretical value of 1.5 , offering some reassurance that the results are reasonable. Using the parameterized storage-discharge equation, we estimated the mobile storage averaged over the catchment area, needed to produce the mean of the peak monthly flows for all years prior to 1970 . The resulting storage volume can be normalized by the mobile porosity of the aquifer sediments to generate an estimate of the drop in the surface water table depth required to explain the "missing" flow volume after 1970 .

Baseflow trends: using the daily data from 1970 to 2010 , we undertook a baseflow separation using a digital filter (Nathan and McMahon, 1990) and computed the annual baseflow and the baseflow index for each water year. Again, we analysed trends in these indices using the methods described previously. Additionally, we analysed baseflow trends in both the monthly data from 1937 to 2008 and in the daily data available for 1970 onward. For the monthly data, we defined a "baseflow month" as a month in which there was streamflow. This definition implies that $100 \%$ of the flow in these months is from baseflow, a much higher standard than the baseflow index which indicates the proportion of baseflow that occurred through time.

\section{Hypothesis 4: increasing actual evapotranspiration due to expansion of plantations}

We calculated the change in eucalyptus plantation area from 1973 to 2001 by comparing the mapped land uses in both years. We used two sources: a land use map provided by Karnataka State Remote Sensing Application Centre (KSRSAC) and Survey of India topographic sheets. The KSRSAC land use map was derived from Indian Remote Sensing (IRS) LISS-3 merged with PAN satellite imagery with an effective $6 \mathrm{~m}$ resolution. The map reported the area under eucalyptus plantations in 2001. For other years, no such maps were readily available. So we digitized 1:50000 scale topographic maps prepared by the Survey of India during the 1970s (1973 to 1979), which show eucalyptus plantations on public lands.

We made three assumptions about water use by eucalyptus plantations (which are typically unirrigated). First, the plantations could not themselves have led to groundwater mining (as has been claimed in other parts of Karnataka (Calder et al., 1993)), because shallow groundwater in the region had largely disappeared by time eucalyptus plantations were promoted under the social forestry programme in the early 1980s. Second, we assumed that eucalyptus transpires at a rate of $830 \mathrm{~mm} \mathrm{yr}^{-1}$ (the annual average rainfall). In effect the trees were perfectly efficient in utilization of rainwater, given that potential evaporation of $1650 \mathrm{~mm} \mathrm{yr}^{-1}$ greatly exceeds annual rainfall and that many plantations implement practices to limit surface runoff. Third, we assumed the plantations displaced rain-fed coarse cereal crops such as maize or millet, which have a seasonal ET of about $290 \mathrm{~mm} \mathrm{yr}^{-1}$ for a single crop and $540 \mathrm{~mm} \mathrm{yr}^{-1}$ for a double crop (Allen et al., 1998).

\section{Hypothesis 5: million puddle theory}

Data on the number of channel obstructions in the TG Halli catchment were available in a report commissioned by Cauvery Neeravari Nigam Limited (CNNL) (CNNL, 2010). A total of 344 obstructive structures were recorded including roads, bridges and unculverted roads, of which 277 were small check dams (Table 2). The density of check dams estimated from the report is $0.2 \mathrm{~km}^{-2}$ of watershed.

To validate the CNNL data, we conducted a comprehensive survey of all stream obstructions in two milli-watersheds covering a $26 \mathrm{~km}^{2}$ area within in TG Halli catchment. Over 40 check dams were found in the $26 \mathrm{~km}^{2}$ area, indicating a check-dam density of $1.35 \mathrm{~km}^{-2}$. Even after discounting $20 \%$ that were leaky or silted, it appears that the CNNL data 
Table 2. Number and type of stream encroachments in each section TG Halli catchment source: Zoomin Tech Report to CNNL, 2011.

\begin{tabular}{lccc}
\hline Type & Hesaraghatta & Kumudvathy & Arkavathy \\
\hline Check dam & 70 & 65 & 142 \\
Bridge & 4 & 23 & 31 \\
Road & 0 & 2 & 7 \\
\hline
\end{tabular}

are an underestimate of the number of check dams. We therefore assumed the higher density of $1.35 \mathrm{~km}^{-2}$ for our analysis.

The volumes of typical obstructions were estimated based on stream profiles made using a dumpy-level instrument on seven check dams. Interpolation of the stream profiles allowed us to estimate the maximum storage volumes as ranging between 100 and $1500 \mathrm{~m}^{3}$ with an average of $325 \mathrm{~m}^{3}$. We multiplied this storage by the basin area and density of obstructing structures to obtain a peak storage volume for the whole basin.

We then plotted the cumulative density function of the daily inflow events into the TG Halli for 15 years from 1976 to 1990 (the period before check dams and unculverted roads were constructed for which we had daily inflow records). We took all flow events less than or equal to the peak storage volume and assumed that the entire flow would be impounded. For events that generated inflows greater than the peak storage, the volume impounded was capped by the peak storage the catchment; anything higher would have overflowed. The volumes impounded were summed to estimate the total loss downstream. This calculation is likely to overestimate the fraction of daily runoff that is impounded behind check dams and unculverted roads, since the structures are unlikely to be empty at the beginning of every rain event.

\section{Results}

Results are presented separately for each of the hypotheses.

\section{Hypothesis 1: declining rainfall}

Annual rainfall trends: Fig. $2 \mathrm{~b}$ shows the area-averaged monthly and annual rainfall over the basin for the years 1934-2010. With an average of $830 \mathrm{~mm} \mathrm{yr}^{-1}$ and standard deviation of $210 \mathrm{~mm} \mathrm{yr}^{-1}$, the monthly rainfall time series does not show any trend, and no statistically significant trend emerges in the annual rainfall. Similarly, no significant changes are visible in the pre- and post-1970 in mean annual and monthly rainfall totals. The data do exhibit high decadal variability in rainfall, and it is clear that the 1970-1980 period was exceptionally wet. However, there is no evidence that total rainfall volumes have changed in the region.

Seasonal rainfall trends: with the exception of Devanahalli, we did not identify any statistically significant shifts in the timing of the rainfall over the last 80 years. The observed trend in Devanahalli was for an increase in JJAS rainfall, contrary to the predictions of climate models. Moreover, more rain in JJAS cannot explain the decline in flow production at other times of the year.

Change in rainfall intensity: no statistically significant trends in daily rainfall volumes exceeding threshold values of 10,25 or $50 \mathrm{~mm}$ could be identified at the 95 th percentile level at any of the four gauges. Although we cannot exclude the possibility of changes in sub-daily rainfall intensities, analysis of rainfall data in the TG Halli catchment area shows no meaningful historical trends in precipitation volumes, timing or storm characteristics. We find no evidence that rainfalldriven changes could be responsible for the change in flow in the TG Halli catchment.

\section{Hypothesis 2: increasing ET due to increase in temperature}

The rise in temperature of about 0.6 to $1{ }^{\circ} \mathrm{C} / 100$ years was within the range predicted by other studies (Kothawale and Rupa Kumar, 2005; Arora et al., 2005). The estimated PET from the Hargreaves equation averaged to the annual scale is shown in Fig. 2c. As indicated in the figure, there is no statistically significant trend in PET within the basin. We conclude that there is no evidence to support the hypothesis that increasing temperature is increasing potential evaporation and leading to a decline in streamflow.

\section{Hypothesis 3: declining baseflow due to groundwater overexploitation}

From the recession analysis, the fitted storage discharge relationship for the pre-1970 period was

$S=595 Q^{0.57}$

where $S$ and $Q$ are given in units of ML per month, consistent with the monthly time step. The slope of the lower envelope was 1.43 , very close to the 1.5 slope predicted by the nonlinear Dupuit-Boussinesq theory and found by Brutsaert and Nieber (1977) in their original analysis. We estimated $S$ for the mean of the peak monthly flows from the years prior to 1970 (65000 ML) using Eq. (7) and normalized this total stored volume by the catchment area. This leads to a prediction that, on average, mobile storage would need to decline by $0.24 \mathrm{~m}$ across the catchment to reduce the peak monthly flow rates to zero. We can then use porosity estimates of $20 \%$ for the unconfined sediments and $1 \%$ for the fractured rock to estimate the order of magnitude of the groundwater declines that could effectively remove $0.24 \mathrm{~m}$ of mobile water from being in connection with the surface channels. This works out to a decline of approximately $1.25 \mathrm{~m}$ in the surficial aquifer, or a decline of approximately $25 \mathrm{~m}$ in the fractured rock aquifer (Fig. 3). 


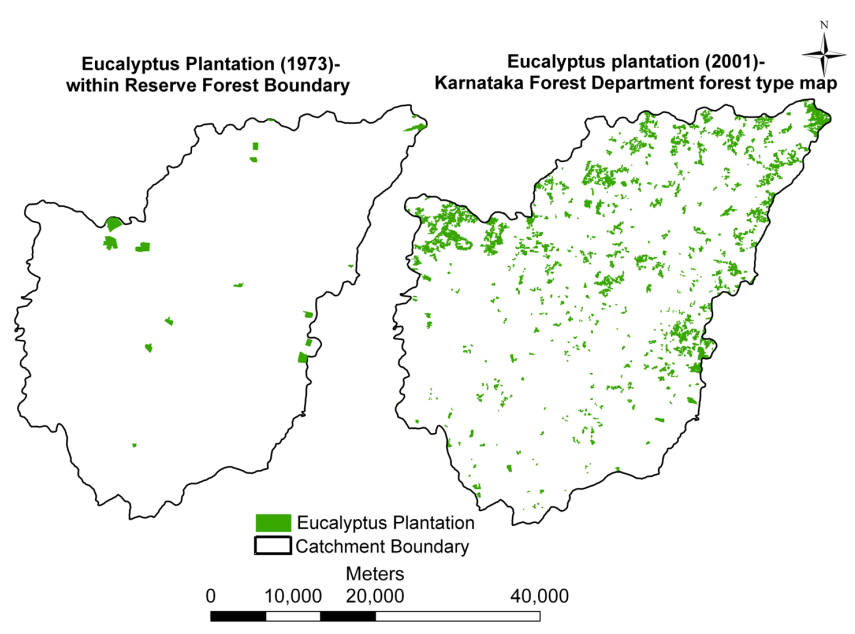

Figure 4. Change in eucalyptus area in Arkavathy Basin between 1973 and 2001.

As can be seen from Fig. 2d, baseflow started declining after the early 1980s, but after 1992 there was not a single month when there was baseflow into the reservoir. The baseflow index, which was computed from daily data and indicates the share of baseflow in the total annual inflow, also declined consistently from 1970 to 2010 . The loss of belowground storage observed in the Arkavathy Basin is of the correct order of magnitude to explain the contemporary absence of surface flow and the hypothesis that loss of groundwater storage in the surface aquifer should be retained for further investigation.

\section{Hypothesis 4: increasing actual evapotranspiration due to expansion of plantations}

The area under eucalyptus plantations in 1973 , as indicated by Survey of India toposheets, was only $11 \mathrm{~km}^{2}$, all of it within the boundaries of state reserve forests. By 2001, the area under eucalyptus plantations had increased to $104 \mathrm{~km}^{2}$ (Fig. 4).

Conversion of $93 \mathrm{~km}^{2}$ of rain-fed crops to eucalyptus plantations would thus translate into a loss of runoff of $75-135 \mathrm{ML} \mathrm{day}^{-1}$ by the year 2001 . This figure is significant compared to the observed runoff decline of about $320 \mathrm{MLday}^{-1}$, suggesting that expansion of eucalyptus could be a significant contributor.

\section{Hypothesis 5: million puddle theory}

Based on the assumptions about check dam and encroachment water storage, the total loss in runoff at the basin scale attributable to channel encroachment is on the order of 18$54 \mathrm{ML} \mathrm{day}^{-1}$. While there are substantial uncertainties associated with this number (for example, other sources of surface water storage such as within-farm impoundments or impoundments in housing plots are ignored leading to an un- derestimate of the total volume, while the assumption that all storages empty prior to each rainfall event undoubtedly represents an overestimate), the order of magnitudes unequivocally indicate that, while the million puddle theory could have contributed to a fraction of the loss in runoff, it cannot account for the entire loss of inflow into the TG Halli.

\section{Discussion}

Our analysis indicates that rainfall changes or temperature increases cannot account for any significant fraction of the decline in inflows into TG Halli reservoir. The causes found to be plausible are groundwater extraction, expansion of eucalyptus plantations and to some extent increased obstructions in the stream course. Importantly, many policy approaches currently under consideration do not reflect the major underlying causes of the drying of the Arkavathy River, and in some cases (check dam construction) they are clearly counter-productive. In the future, climate change could play a critical role in exacerbating water stress, but climate stressors will only add to existing local stresses.

Although the hypotheses have been framed as independent, the mechanisms undoubtedly interact with each other, so their inter-relations should be considered in formulating a conceptual model of the catchment and in attributing the effects of each mechanism in terms of the change in river flow. For example, check dams not only impound flow, but also locally elevate recharge. Check dams may thus facilitate high levels of groundwater extraction locally. Spatial heterogeneity in water table levels and eucalyptus root zone access to saturated conditions may vary throughout the catchment, meaning that the assumption that eucalyptus plantations do not contribute to groundwater mining and reduced baseflow should be relaxed in future studies.

The analysis presented here is preliminary. Further work is needed to understand the hydrological processes in the catchment, including the contemporary and historical flow generation pathways and their changes. There are, however, suggestive clues of timing that suggest a potential working hypothesis for the flow generation mechanisms. Expansion of electricity and installation of wells began to increase in the late 1960s - although this period also coincided with a period of relatively high rainfall and streamflow in the 1970s. Flow declines began to emerge in the early 1980s, with baseflow indices and numbers of "baseflow months" plummeting in the early 1990s, approximately at the same time that open wells went dry and deeper boreholes become more prevalent (Fig. 3a, b). During this period, the baseflow index declined, suggesting that less and less of the streamflow entering the TG Halli reservoir was associated with groundwater inputs. These trends are highly reminiscent of those projected by models of the Republican River basin (Zeng and Cai, 2014) as a function of increasing groundwater extraction-reduced baseflow and an increasingly erratic quick-flow response. 
Inflows continued to decline after 1992, suggesting that additional mechanisms beyond the decline in baseflow must be considered. Possible additional mechanisms include the conversion of the Arkavathy River into a "losing" river, which provides a source of recharge to the local aquifers, the continued expansion of eucalyptus plantations and increasing implementation of management techniques that prevent surface runoff from leaving farm fields and increasing obstruction of the stream channels. Based on these observations, further research targeting runoff generation mechanisms, establishing the pathways for surface-groundwater connections, evaluating the effect of land use on water balance and estimating groundwater extraction rates has now been initiated in the catchment (see www.atree.org/accuwa).

Finally, from a policy perspective, the fuzzy perception of the causes of streamflow decline and the lack of coordination between agencies have resulted in contradictory policies. The range of policy responses observed reflect both different stakeholder interests and different explanations of the hydrologic causes of the declining river flow. For instance, even as CNNL is removing encroachments and blockages under the programme to rejuvenate the Arkavathy River, new check dams continue to be authorized under the Mahatma Gandhi Rural Employment Guarantee Scheme (MNREGA). Interestingly, the case study illustrates that the reluctance to acknowledge human feedback is not limited to hydrologists. Even farmers living in the catchment often do not fully acknowledge their role in altering the hydrology. The actors involved have not made any substantive effort to scientifically validate and reconcile these views, resulting in significant wasted investment.

\section{Conclusions}

The TG Halli catchment case study shows that humans can play a significant role in altering the hydrology of watersheds (Wang and Cai, 2009; Grafton et al., 2013) in a variety of ways. Indeed, the results presented in this paper suggest that proximate drivers like groundwater pumping and land use change, rather than just climate change, are the most likely causes of the drying of the Arkavathy River. The article strengthens the case for use-inspired sociohydrology as a science of water and society that explicitly includes human feedback on hydrologic processes (Sivapalan et al., 2012). In particular, the paper makes three contributions to this nascent field. First, the study highlights the importance of accounting for multiple anthropogenic drivers of change. There has been a tendency within the hydrology community to understate the role of humans in altering hydrology beyond large structures like dams or, more recently, climate change. The dominant conceptualization remains that of the hydrologic system as being separate from society. This case study shows why attention to direct and dispersed human modifications of this system is needed. Second, the study offers guidance on how human feedback ought to be addressed in a region where data are scarce and unreliable. By adopting a multiple-hypothesis approach, we illustrate how even limited data sources can be marshalled to eliminate some of them and identify critical knowledge gaps. This approach can inform primary data collection efforts and lead to the development of better models of the catchment.

Third, the hypotheses themselves are derived not just from the academic literature but also from perceptions of all stakeholders in the debate. This ensures the legitimacy and usefulness of the research.

Acknowledgements. This research is part of a larger study titled "Adapting to Climate Change in Urbanizing Watersheds (ACCUWa) in India" (www.atree.org/accuwa).

We are grateful to Jayalakshmi from ATREE's EcoInformatic Lab for RS/GIS support and Sowmyashree for help with the 1973 Eucalyptus area calculation. We thank NIT Suratkal student D. N. Shilpa and ATREE Administrative Assistant H. Usha for translation and data entry support on the annual season crop reports. We thank our outreach coordinators K. Janardhan and G. Manjunath for the insights obtained from water literacy meetings. We are grateful to Sekhar Muddu and the other ACCUWa advisory committee members for input on the hydrology study. We are grateful to P. N. Ballukraya for sharing his borehole data and advice on the hydrogeology investigations.

Financial support for most of this research comes from grant no. 107086-001 from the International Development Research Centre (IDRC), Canada. In addition, S. Thompson acknowledges NSF CNIC IIA-1427761 for support of ATREE-UC Berkeley collaborations. G. Penny acknowledges support from the NSF Graduate Research Fellowship Program under grant no. DGE 1106400, the NSF and USAID Research and Innovation Fellowship Program and NSF International Research Experience for Students (OISE-1031194).

Edited by: M. Sivapalan

\section{References}

Allen, R. G., Pereira, L. S., Raes, D., and Smith, M.: Crop evapotranspiration - Guidelines for computing crop water requirements, FAO Irrigation and drainage paper 56, FAO, Rome, 300, 6541, 1998.

Arora, M., Goel, N., and Singh, P.: Evaluation of temperature trends over India/Evaluation de tendances de température en Inde, Hydrol. Sci. J., 50, 81-93, 2005.

Arrigoni, A. S., Greenwood, M. C., and Moore, J. N.: Relative impact of anthropogenic modifications versus climate change on the natural flow regimes of rivers in the Northern Rocky Mountains, United States, Water Resour. Res., 46, W12542, doi:10.1029/2010WR009162, 2010.

Arzberger, P., Schroeder, P., Beaulieu, A., Bowker, G., Casey, K., Laaksonen, L., Moorman, D., Uhlir, P., and Wouters, P.: An international framework to promote access to data, Science, American Association for the Advancement of Science, 1777-1778, 2004. 
Bonell, M., McDonnell, J., Scatena, F., Seibert, J., Uhlenbrook, S., and van Lanen, H.: HELPing FRIENDs in PUBs: charting a course for synergies within international water research programmes in gauged and ungauged basins, Hydrol. Process., 20, 1867-1874, 2006.

Brown, A. E., Zhang, L., McMahon, T. A., Western, A. W., and Vertessy, R. A.: A review of paired catchment studies for determining changes in water yield resulting from alterations in vegetation, J. Hydrol., 310, 28-61, doi:10.1016/j.jhydrol.2004.12.010, 2005.

Brutsaert, W. and Nieber, J. L.: Regionalized drought flow hydrographs from a mature glaciated plateau, Water Resour. Res., 13, 637-643, 1977.

Buytaert, W.: Interactive comment on "Why is the Arkavathy River drying? A multiple hypothesis approach in a data scarce region", HESS Interactive Comment, 12, 2015.

Buytaert, W., Zulkafli, Z., Grainger, S., Acosta, L., Bastiaensen, J., De Bièvre, B., Bhusal, J., Chanie, T., Clark, J., Dewulf, A., Foggin, M., Hannah, D. M., Hergarten, C., Isaeva, A., Karpouzoglou, T., Pandeya, B., Paudel, D., Sharma, K., Steenhuis, T., Tilahun, S., Zhumanova, M., and Van Hecken, G.: Citizen science in hydrology and water resources: opportunities for knowledge generation, ecosystem service management, and sustainable development, Front. Earth Sci., 2, 26, doi:10.3389/feart.2014.00026, 2014

Cai, X. and Zeng, R.: Assessing the Stream Flow Effects of Groundwater Pumping and Return Flow from Irrigation, Chap. 40, 416425, doi:10.1061/9780784412947.040, 2013.

Calder, I. R., Hall, R. L., and Prasanna, K.: Hydrological impact of Eucalyptus plantation in India, J. Hydrol., 150, 635-648, doi:10.1016/0022-1694(93)90129-W, 1993.

Chamberlin, T. C.: The method of multiple working hypotheses, Science, 15, 754-759, doi:10.1126/science.148.3671.754, 1965.

Chattopadhyay, N. and Hulme, M.: Evaporation and potential evapotranspiration in India under conditions of recent and future climate change, Agr. Forest Meteorol., 87, 55-73, 1997.

CNNL: Study of Obstructions to flow of natural water in the course of the Arkavathy River and its tributaries from the origin upto the Thippagondanahalli reservoir, Cauvery Neeravari Nigam Limited, Bangalore 560061, 2010.

DES: Annual season crop report for 1970-2012, Government of Karnataka, Bangalore, India, 1970-2012.

Duffie, J. and Beckman, W.: Solar Engineering of Thermal Processes, Hoboken, New Jersey, 3 Edn., 2013.

Dunne, T. and Leopold, L.: Water in environmental planning, W. H. Freeman and Co., San Francisco, CA, 1978

Farley, K. A., Jobbagy, E. G., and Jackson, R. B.: Effects of afforestation on water yield: a global synthesis with implications for policy, Global Change Biol., 11, 1565-1576, doi:10.1111/j.1365-2486.2005.01011.x, 2005.

Garg, K. K., Wani, S. P., Barron, J., Karlberg, L., and Rockstrom, J.: Up-scaling potential impacts on water flows from agricultural water interventions: opportunities and trade-offs in the Osman Sagar catchment, Musi sub-basin, India, Hydrol. Process., 27, 3905-3921, 2013.

Gosain, A., Rao, S., and Basuray, D.: Climate change impact assessment on hydrology of Indian river basins, Curr. Sci., 90, 346353,2006
Gosain, A., Rao, S., and Arora, A.: Climate change impact assessment of water resources of India, Curr. Sci. (Bangalore), 101, 356-371, 2011.

Grafton, R. Q., Pittock, J., Davis, R., Williams, J., Fu, G., Warburton, M., Udall, B., McKenzie, R., Yu, X., Che, N., Connell, D., Jiang, Q., Kompas, T., Lynch, A., Norris, R., Possingham, H., and Quiggin, J.: Global insights into water resources, climate change and governance, Nat. Clim. Change, 3, 315-321, doi:10.1038/nclimate1746, 2013.

Hargreaves, G. H. and Allen, R. G.: History and evaluation of Hargreaves evapotranspiration equation, J. Irrig. Drain. Eng., 129, 53-63, doi:10.1061/(ASCE)0733-9437(2003)129:1(53), 2003.

Hargreaves, G. H. and Samani, Z. A.: Reference crop evapotranspiration from ambient air temperature, Am. Soc. Agr. Eng., 1, 96-99, 1985.

Hingane, L., Rupa Kumar, K., and Ramana Murty, B. V.: Longterm trends of surface air temperature in india, J. Climatol., 5, 521-528, doi:10.1002/joc.3370050505, 1985.

Hu, Z., Wang, L., Wang, Z., Hong, Y., and Zheng, H.: Quantitative assessment of climate and human impacts on surface water resources in a typical semi-arid watershed in the middle reaches of the Yellow River from 1985 to 2006, Int. J. Climatol., 35, 97113, 2015.

Huntington, T. G.: Evidence for intensification of the global water cycle: review and synthesis, J. Hydrol., 319, 83-95, 2006.

ISRO and IN-RIMT: Tippagondanahalli Reservoir (TGR): A remote sensing based evaluation, Technical report for Bangalore Metropolitan Region Development Authority, Bengaluru, 2000.

Kelkar, U., Narula, K. K., Sharma, V. P., and Chandna, U.: Vulnerability and adaptation to climate variability and water stress in Uttarakhand State, India, Global Environ. Change, 18, 564-574, 2008.

Kothawale, D. and Rupa Kumar, K.: On the recent changes in surface temperature trends over India, Geophys. Res. Lett., 32, L18714, doi:10.1029/2005GL023528, 2005.

Lele, S., Srinivasan, V., Jamwal, P., Thomas, B., Eswar, M., and Zuhail, T. M.: Water Management in Arkavathy Basin: A Situation Analysis, Environ. Develop., Discussion Paper 1, 2013.

Maeda, E. and Torres, J.: Open Environmental Data in Developing Countries: Who Benefits?, AMBIO, 41, 410-412, doi:10.1007/s13280-012-0283-4, 2012.

Maurer, E.: Extraterrestrial solar radiation calculator, available at: http://www.engr.scu.edu/ emaurer/tools/calc_solar_cgi. pl (last access: 13 April 2015), 2014.

McVicar, T. R., Roderick, M. L., Donohue, Randall J.and Li, L. T., Van Niel, T. G., Thomas, A., Grieser, J., Jhajharia, D., Himri, Y., Mahowald, N. M., Mescherskaya, A. V., Kruger, A. C., Rehman, S., and Dinpashoh, Y.: Global review and synthesis of trends in observed terrestrial near-surface wind speeds: Implications for evaporation, J. Hydrol., 416, 182-205, doi:10.1016/j.jhydrol.2011.10.024, 2012.

Milly, P., Betancourt, J., Falkenmark, M., Hirsch, R., Kundzewicz, Z., Lettenmaier, D., and Stouffer, R.: Stationarity is dead: Whither water management?, Science, 319, 573-574, doi:10.1126/science.1151915, 2008.

Mujumdar, P. and Ghosh, S.: Modeling GCM and scenario uncertainty using a possibilistic approach: Application to the Mahanadi River, India, Water Resour. Res., 44, W06407, doi:10.1029/2007WR006137, 2008. 
Nathan, R. and McMahon, T.: Evaluation of Automated Techniques for Baseflow and Recession Analysis, Water Resour. Res., 26, 1465-1473, doi:10.1029/WR026i007p01465, 1990.

Ramanathan, V., Chung, C., Kim, D., Bettge, T., Buja, L., Kiehl, J., Washington, W., Fu, Q., Sikka, D., and Wild, M.: Atmospheric brown clouds: Impacts on South Asian climate and hydrological cycle, P. Natl. Acad. Sci. USA, 102, 5326-5333, 2005.

Reichman, O., Jones, M., and Schildhauer, M.: Challenges and opportunities of open data in ecology, Science (Washington), 331, 703-705, 2011.

Shah, E.: Social designs: Tank irrigation technology and agrarian transformation in Karnataka, South India, Vol. 4, Orient Longman Hyderabad, 2003.

Shiva, V., Sharatchandra, H., and Bandyopadhyay, J.: Social, economic, and ecological impact of social forestry in Kolar, Indian Institute of Management, 1981.

Sivapalan, M.: Prediction in ungauged basins: a grand challenge for theoretical hydrology, Hydrol. Process., 17, 3163-3170, doi:10.1002/hyp.5155, 2003.

Sivapalan, M., Takeuchi, K., Franks, S., Gupta, V., Karambiri, H., Lakshmi, V., Liang, X., McDonnell, J., Mendiondo, E., O'Connell, P., Oki, T., Pomeroy, J., Schertzer, D., Uhlenbrook, S., and Zehe, E.: IAHS Decade on Predictions in Ungauged Basins (PUB), 2003-2012: Shaping an exciting future for the hydrological sciences, Hydrol. Sci. J., 48, 857-880, 2003.

Sivapalan, M., Savenije, H. H., and Blöschl, G.: Socio-hydrology: A new science of people and water, Hydrol. Process., 26, 12701276, doi:10.1002/hyp.8426, 2012.

Sivapalan, M., Konar, M., Srinivasan, V., Chhatre, A., Wutich, A., Scott, C., Wescoat, J., and Rodríguez-Iturbe, I.: Socio-hydrology: Use-inspired water sustainability science for the Anthropocene, Earth's Future, 2, 225-230, doi:10.1002/2013EF000164, 2014.

Spencer, J.: Solar position and radiation tables for Brisbane (latitude 27. 5/sup 0/S), Tech. Rep., Commonwealth Scientific and Industrial Research Organization, Melbourne (Australia), 1971.

Srinivasan, V., Lambin, E., Gorelick, S., Thompson, B., and Rozelle, S.: The nature and causes of the global water crisis: Syndromes from a meta-analysis of coupled human-water studies, Water Resour. Res., 48, 10, doi:10.1029/2011WR011087, 2012a.

Srinivasan, V., Seto, K. C., Emerson, R., and Gorelick, S. M.: The impact of urbanization on water vulnerability: A coupled human-environment system approach for Chennai, India, Global Environ. Change, doi:10.1016/j.gloenvcha.2012.10.002, 2012 b.
Stocker, T. F. and Raible, C. C.: Climate change: water cycle shifts gear, Nature, 434, 830-833, doi:10.1038/434830a, 2005.

Systematics, C.: Data \& Capacity Needs for Transportation NAMAs Report 1: Data Availability, 2010.

Thompson, S. E., Sivapalan, M., Harman, C. J., Srinivasan, V., Hipsey, M. R., Reed, P., Montanari, A., and Blöschl, G.: Developing predictive insight into changing water systems: useinspired hydrologic science for the Anthropocene, Hydrol. Earth Syst. Sci., 17, 5013-5039, doi:10.5194/hess-17-50132013, 2013.

Vaidyanathan, A.: Tanks of South India, Centre for Science and Environment New Delhi, India, 2001.

Vörösmarty, C. J., McIntyre, P., Gessner, M. O., Dudgeon, D., Prusevich, A., Green, P., Glidden, S., Bunn, S. E., Sullivan, C. A., Liermann, C. R., Reidy, C., and Davies, P. M.: Global threats to human water security and river biodiversity, Nature, 467, 555$561,2010$.

Wagener, T., Sivapalan, M., McDonnell, J., Hooper, R., Lakshmi, V., Liang, X., and Kumar, P.: Predictions in ungauged basins as a catalyst for multidisciplinary hydrology, Eos, Trans. Am. Geophys. Union, 85, 451-457, 2004.

Wagener, T., Sivapalan, M., Troch, P. A., McGlynn, B. L., Harman, C. J., Gupta, H. V., Kumar, P., Rao, P. S. C., Basu, N. B., and Wilson, J. S.: The future of hydrology: An evolving science for a changing world, Water Resour. Res., 46, doi:10.1029/2009WR008906, 2010.

Wang, D. and Cai, X.: Detecting human interferences to low flows through base flow recession analysis, Water Resour. Res., 45, W07426, doi:10.1029/2009WR007819, 2009.

Wang, D. and Hejazi, M.: Quantifying the relative contribution of the climate and direct human impacts on mean annual streamflow in the contiguous United States, Water Resour. Res., 47, W00J12, doi:10.1029/2010WR010283, 2011.

Zeng, R. and Cai, X.: Analyzing streamflow changes: irrigationenhanced interaction between aquifer and streamflow in the Republican River basin, Hydrol. Earth Syst. Sci., 18, 493-502, doi:10.5194/hess-18-493-2014, 2014. 